Review

\title{
Research challenges for cultural ecosystem services and public health in (peri-)urban environments
}

\author{
Xianwen Chen $^{\mathrm{a}, *}$, Sjerp de Vries ${ }^{\mathrm{b}}$, Timo Assmuth ${ }^{\mathrm{c}, 1}$, Jan Dick ${ }^{\mathrm{l}, 1}$, Tia Hermans ${ }^{\mathrm{b}, 1}$, Ole Hertel ${ }^{\mathrm{d}, 1}$, Anne Jensen ${ }^{\mathrm{e}, 1}$, \\ Laurence Jones $^{\mathrm{f}, 1}$, Sigrun Kabisch ${ }^{\mathrm{g}, 1}$, Timo Lanki ${ }^{\text {h,i,1, }}$, Irina Lehmann ${ }^{\mathrm{j}, 1}$, Lindsay Maskell ${ }^{\mathrm{k}, 1}$, \\ Lisa Norton ${ }^{\mathrm{k}, 1}$, Stefan Reis $1, \mathrm{~m}, 1$ \\ a Department of Landscape Ecology, Norwegian Institute for Nature Research, C/o NINA, Gaustadalleen 21, 0349 Oslo, Norway \\ b Wageningen Environmental Research, Wageningen University E Research, PO Box 47, 6700AA Wageningen, the Netherlands \\ c Finnish Environment Institute (SYKE), P.O. Box 140, FI-00251 Helsinki, Finland

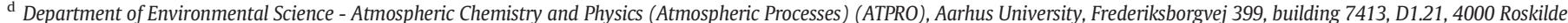 \\ Denmark \\ e Department of Environmental Science - Enviromental Social Science, Aarhus University, Frederiksborgvej 399, building 7420, K1.13, 4000 Roskilde, Denmark \\ ${ }^{\mathrm{f}}$ Centre for Ecology \& Hydrology, Environment Centre Wales, Deiniol Road, Bangor, Gwynedd LL57 2UW, UK \\ g Department of Urban and Environmental Sociology, Helmholtz Centre for Environmental Research - UFZ, Permoserstraße 15, 04318 Leipzig, Germany \\ ${ }^{\text {h }}$ Department of Health Security, National Institute for Health and Welfare (THL), P.O. Box 95, FI-70701 Kuopio, Finland \\ ${ }^{\mathrm{i}}$ Institute of Public Health and Clinical Nutrition, University of Eastern Finland, Kuopio, Finland \\ ${ }^{\mathrm{j}}$ Berlin Institute of Health, Charité - Universitätsmedizin Berlin, Berlin, Germany \\ ${ }^{\mathrm{k}}$ Centre for Ecology \&' Hydrology, Lancaster Environment Centre, Library Avenue, Bailrigg, Lancaster LA1 4AP, UK \\ ${ }^{1}$ Centre for Ecology \&' Hydrology, Bush Estate, Penicuik, Midlothian EH26 0QB, UK \\ ${ }^{m}$ University of Exeter Medical School, Knowledge Spa, Truro TR1 3HD, UK
}

\section{H I G H L I G H T S}

- Concerns positive public health impacts of urban nature's cultural ecosystem services (CES).

- Discusses global development trends' implications for the provision and demand of CES.

- Discusses current research and key research questions for a new research agenda.

\section{G R A P H I C A L A B S T R A C T}

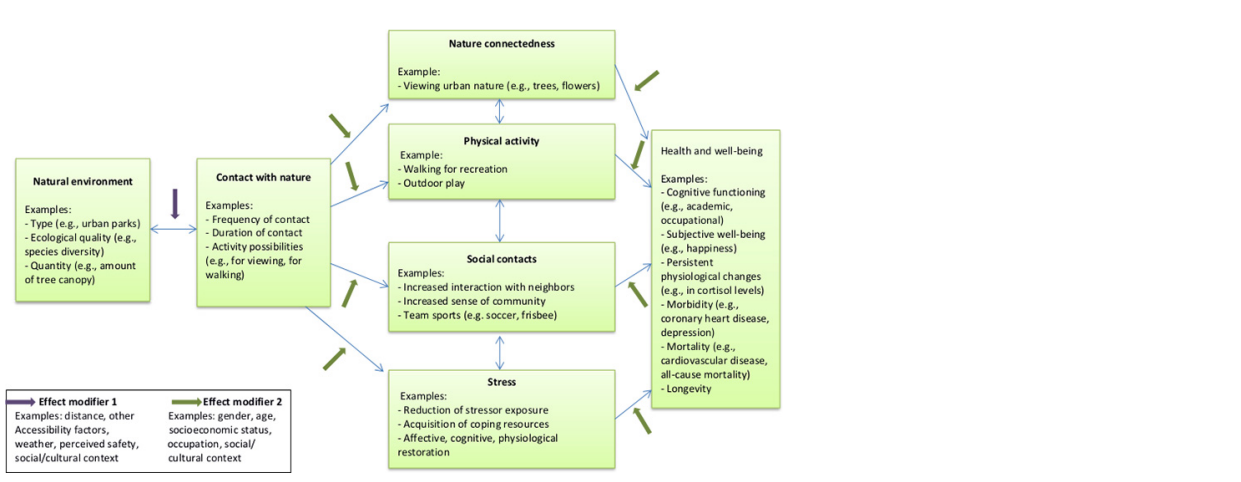

\section{A R T I C L E I N F O}

\section{Article history:}

Received 5 July 2018

Received in revised form 3 September 2018

Accepted 3 September 2018

Available online 5 September 2018

\begin{abstract}
A B S T R A C T
Urbanization is a global trend, and consequently the quality of urban environments is increasingly important for human health and wellbeing. Urban life-style is typically associated with low physical activity and sometimes with high mental stress, both contributing to an increasing burden of diseases. Nature-based solutions that make effective use of ecosystem services, particularly of cultural ecosystem services (CES), can provide vital building blocks to address these challenges. This paper argues that, the salutogenic, i.e. health-promoting effects
\end{abstract}

\footnotetext{
* Corresponding author.

E-mail addresses: xianwen.chen@nina.no (X. Chen), sjerp.devries@wur.nl (S. de Vries), timo.assmuth@ymparisto.fi (T. Assmuth), jand@ceh.ac.uk (J. Dick), tia.hermans@wur.nl (T. Hermans), oh@envs.au.dk (O. Hertel), aj@envs.au.dk (A. Jensen), lj@ceh.ac.uk (L. Jones), sigrun.kabisch@ufz.de (S. Kabisch), timo.lanki@thl.fi (T. Lanki), irina.lehmann@bihealth.de (I. Lehmann), lcma@ceh.ac.uk (L. Maskell),lrn@ceh.ac.uk (L. Norton), srei@ceh.ac.uk (S. Reis).

1 The third to the last authors are listed alphabetically by last name.
} 
Editor: Frederic Coulon

\section{Keywords:}

Cultural ecosystem services

Public health

Urban green/blue infrastructure

Nature-based solutions of CES have so far not been adequately recognised and deserve more explicit attention in order to enhance decision making around health and wellbeing in urban areas. However, a number of research challenges will need to be addressed to reveal the mechanisms, which underpin delivery of urban CES. These include: causal chains of supply and demand, equity, and equality of public health benefits promoted. Methodological challenges in quantifying these are discussed. The paper is highly relevant for policy makers within and beyond Europe, and also serves as a review for current researchers and as a roadmap to future short- and long-term research opportunities.

(c) 2018 The Authors. Published by Elsevier B.V. This is an open access article under the CC BY-NC-ND license (http://creativecommons.org/licenses/by-nc-nd/4.0/).

\section{Contents}

1. Introduction . . . . . . . . . . . . . . . . . . . . . . . . . . . . . . . . . . . . . . . . . . . . . . . . 2119

2. Development trends and their implications for the provision and demand of CES . . . . . . . . . . . . . . . . . . . . . . . . 2120

2.1. Global environmental trends . . . . . . . . . . . . . . . . . . . . . . . . . . . . . . . . . . . . . . . . . 2120

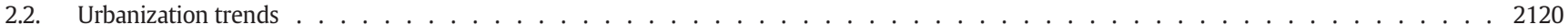

2.3. Social trends. . . . . . . . . . . . . . . . . . . . . . . . . . . . . . . . . . . . . . . . 2120

2.4. Political and policy trends in Europe . . . . . . . . . . . . . . . . . . . . . . . . . . . . . . . . . . . . . 2121

3. Functional relationships between CES and the health and well-being of human societies. . . . . . . . . . . . . . . . . . . . . . . . . . 2122

4. Current research and key topical research questions for a new research agenda. . . . . . . . . . . . . . . . . . . . . . . . . . . . . . 2123

4.1. Mechanisms and outcomes: How does the use of CES affect health and well-being? . . . . . . . . . . . . . . . . . . . . . . . . 2123

4.2. Mapping and modelling of CES: Supply, demand and use . . . . . . . . . . . . . . . . . . . . . . . . . . . . . . . . . . . . . . . 2124

4.3. Environmental equity and socioeconomic health differences . . . . . . . . . . . . . . . . . . . . . . . . . . . . . . . . . . . . 2125

4.4. Knowledge on action: Institutions, norms and policies, strategies and plans, governance and collaboration, technologies and communication, and

other capabilities and prerequisites of interventions . . . . . . . . . . . . . . . . . . . . . . . . . . . . . . . 2125

5. Methodologies and R\&D approaches . . . . . . . . . . . . . . . . . . . . . . . . . . . . . . . . . . . . . . . . . . . . . . . . 2126

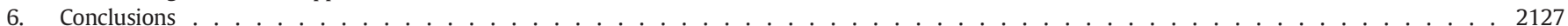

Acknowledgement. . . . . . . . . . . . . . . . . . . . . . . . . . . . . . . . . . . . . . . . . . 2127

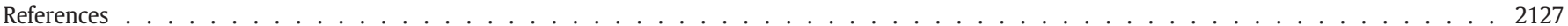

\section{Introduction}

Modern societies face many challenges in their efforts to pursue sustainability under economic stress, demographic and social pressures, political instability and conflict, as well as global environmental change. Urban environments are beneficial to human health and wellbeing in that they provide improved economic possibilities and better access to health care. At the same time, the quality of environment may be low in urban areas, and urban life-style is associated with low physical activity and possibly increased levels of mental stress as well as noncommunicable chronic diseases. Likewise, changing and potentially fast increasing burdens on human and non-human health from infectious and other communicable diseases, including emerging diseases, zoonoses, and pandemic outbreaks, are closely associated with urban environments in Europe as well as in other continents (Degeling et al., 2015; Sikkema and Koopmans, 2016). Nature-based solutions (NBS) that make effective and efficient use of ecosystem services (ES), can provide vital building blocks to address health related challenges, such as improving health equity and maintaining social cohesion.

This paper aims to examine the provision of health and well-being through CES as a scientific and policy and planning issue. Our findings relate to the Sustainable Development Goals (SDGs) (United Nations, 2015), especially "Good Health and Well-Being" (the 3rd goal) and "Reduced Inequality" (the 10th goal). Furthermore, the arguments developed in the paper also fit well within the discussion on new health concepts, including EcoHealth (Charron, 2012; Wilcox et al., 2004), ecological public health (Lang and Rayner, 2012), planetary health (Whitmee et al., 2015), and One Health (Gibbs, 2014; Wallace et al., 2015; Keith et al., 2016) which is a further development of One Medicine. Although these health concepts differ in detail, they share a common focus on integrating and emphasizing the links between ecosystems, domestic and wild animals and other non-human organisms, and human health. Although this paper uses Europe as an example, most of the synthesis of current literature and discussions of future research challenges are applicable to cities and countries in general.

Until now, the focus of studies on urban ES has been mainly on provisioning and regulating services, such as food production, air quality improvement, heat stress amelioration, and water management. However, the salutogenic, i.e. health-promoting effects of cultural ecosystem services (CES) should not be overlooked and deserve more explicit attention (see e.g., Andersson et al., 2015). CES differ from the other categories of ES in that they are primarily the non-material outputs of ecosystems, for example, providing opportunities for recreation, physical activity, socializing, restoring capacities. Unfortunately, such outputs are more difficult to observe, measure, and value (Milcu et al., 2013). Despite the challenges in quantifying CES, these services remain of considerable importance (TEEB, 2016).

The salutogenic orientation is also relevant as a complement to the traditional risk factor based approach to health. It emphasizes health as a positive entity, a dynamic process of development, a multifaceted psychosomatic condition of the whole individual, and a social phenomenon (Antonovsky, 1996). ${ }^{2}$

This paper will focus on final ecosystem services (ES), which are the services that most directly affect human well-being, irrespective of whether the ecosystems generating these final ES are natural, seminatural, or artificial (Haines-Young and Potschin, 2013). In addition, we focus on primary services, i.e. services with a direct (spatial) link to an ecosystem. That is to say that, for instance, creating a painting from directly experiencing the ecosystem is included in the scope of our paper, but activities such as watching nature documentaries or viewing artistic expressions inspired by nature are for the most part excluded. The former activities can be beneficial to health, as suggested also by the biophilia hypothesis (see e.g. Kellert and Wilson, 1993). The latter activities do not have a direct, physical, or spatial link with the service-providing ecosystem. Primary final CES can only be

\footnotetext{
2 See also the definition used by WHO.
} 
consumed in the ecosystem on the location, i.e. people have to come into contact with the ecosystem to enjoy the service. They may deliberately visit the ecosystem, e.g. an urban park, for the health benefit, visit the ecosystem for another reason but enjoy the benefit nevertheless, ${ }^{3}$ or even come into contact with the ecosystem without purposefully visiting it. The last scenario also implies that people may not always be aware of the benefits they gain from coming into contact with nature.

Instead of focusing on curing diseases and disorders once they have occurred, this paper focuses on the prevention of their emergence in residential areas, especially in (peri-)urban areas. ${ }^{4}$ This is in line with the salutogenic approach to health and with evaluations of the importance of prevention and other upstream interventions in health promotion (Andermann et al., 2016). It should however be noted that health promotion in residential settings overlaps with that in occupational environments, in transport, and in non-residential leisure also within public health. While prevention is considered preferable over cure, ${ }^{5}$ preventive effects of CES may be harder to establish, especially when it comes to mental health due to the more complex nature of causal origins and pathways of mental illnesses. This is because the health conditions are non-specific and multi-attribute as well as multi-factorial, and the causal links between them and the contributing factors and mechanisms and the outcomes are complex. At the same time, mental disorders are increasingly adding to the burden of disease in both the developed and the developing parts of the world, in both adults and children. For example, according to the WHO, depression is a leading cause of disability worldwide, and is a major contributor to the overall global burden of disease (WHO, 2015). There are indications that CES are especially relevant for mental health (Van den Berg et al., 2015; Mitchell et al., 2015). Clinical research has increasingly identified links between mental and physiological health also on a physiological and biochemical level (see e.g. Carney et al., 2005), in the way links have been traditionally established between some aspects of somatic health and of engagement with the environment. Notably, as a type of CES, facilitation of physical activities and exercises are beneficial also to somatic health (see e.g. Tzoulas et al., 2007). Taken together, this suggests that CES have the potential to benefit human health in many ways.

However, despite such information from research on the potential importance of CES for human health, essential gaps remain in knowledge and in activities that may fill these gaps. Gaps are related to CESs, to health, to their links, and to their social contexts. These gaps hamper operationalization of core concepts. Gaps are identifiable in both somatic and mental health and on individual and collective levels. There is thus a clear need to analyse and to evaluate them more systematically and in more detail, and to identify opportunities in the generation and use of knowledge in all intervention stages and areas.

The remainder of the paper is organized as follows. After the Introduction, a section addresses development trends and the consequent implications for the provision and demand of CES. The next section describes the functional relationship between CES and the health and well-being of citizens. The following section briefly discusses current research and identifies key research questions on CES and health in (peri-) urban contexts. A section on methodological challenges and research opportunities follows before conclusions are drawn.

\footnotetext{
${ }^{3}$ For example, because urban nature functions as refugia for birds and other wildlife, a visitor to urban nature can potentially psychologically benefit from observing birds and other wildlife.

${ }^{4}$ CES have been associated with both preventative and remedial effects on diseases and health risks. The mechanisms by which CES lead to beneficial preventive health effects may be the same as those that are beneficial with regard to cure and care. However, the field of application differs.

${ }^{5}$ We note that the relevance of distinguishing between prevention and cure is becoming less important. Increasing numbers of people live long while having a chronic disease. They benefit in coping with their disease from living in a salutogenic ecosystem.
}

\section{Development trends and their implications for the provision and demand of CES}

\subsection{Global environmental trends}

Global environmental trends have implications at regional, national, and local levels, for (peri-)urban as well as rural areas. These trends include climate change (long term changes; extreme weather events), with associated changes in hydrological systems (floods, sea level rise), degradation of ecosystems (degradation of land, biodiversity loss, invasions of non-native species), decreasing air, water, and soil quality in many growing cities, and increased competition for use of resources (land, water, energy, food, raw materials) (World Resources Institute, 2014). These environmental changes and processes interact in complex ways with demographic changes (e.g. population growth and ageing), socioeconomic changes (e.g. in wealth distribution and the widening gap between rich and poor; polarization of population groups; redistribution of jobs; changes in consumption patterns), social changes (e.g. smaller household sizes; migration and urbanization patterns) and political changes. All of these affect local environmental quality. These trends and their interaction must be acknowledged when examining the links between health, wellbeing and CES, and must also be considered by policy makers who plan and make decisions regarding (peri-)urban environments.

\subsection{Urbanization trends}

Europe is among the world's most urbanized regions, with approximately $73 \%$ of Europeans living in urban areas, a figure that is expected to increase to $80 \%$ in 2050 (United Nations, 2014). In recent decades, urbanization has taken the form of spatial expansion and densification as well as population growth, making daily access to green space less common (Haaland and van den Bosch, 2015). Ongoing urbanization processes, socio-demographic changes and changes in consumption patterns together with global environmental change put increasing pressures on environmental and human resources, ecosystems, and their services. On the other hand, cities are therefore increasingly also engines of development, and can provide resources, services and benefits. Improving or even maintaining environmental quality for health purposes thus calls for innovative solutions that tackle simultaneously the economic, social, and environmental challenges in cities and utilize their potentials while promoting specifically the well-being of increasingly diverse urban populations. Only in this way can European cities be attractive, inclusive, and sustainable for all in the future (European Commission, 2015). Moreover, because of the extensive impacts of urbanization and the connectedness of urban and rural areas, many solutions need to address them jointly.

Recently, the financial crisis has placed more pressure on urban areas giving rise to socio-spatial divides and rising socio-economic inequalities. Such inequalities often go together with unequal access to environmental resources and to environmental amenities, and with unequal distribution of and exposure to environmental risks and hazards (Bertrand et al., 2015). For example, greening strategies in poorer districts may lead to "eco-gentrification" processes, which cause expulsion of those residents who cannot afford rising costs and rents (Checker, 2011). Thus greening policies are not always socially inclusive. Lowincome groups need particular attention, as do those who have a lower capacity to cope with risks and hazards, e.g. because of weak social support networks due to out-migration and ageing (Kuhlicke et al., 2012). Ethnic diversity and divisions further complicate these trends.

\subsection{Social trends}

Urban environmental inequity is influenced by several social trends. These include intensifying migration, in-/exclusion of specific age 
groups, and social and ethnic segregation. Differences in health statuses appear to correlate with, on the one hand, level of income, education and social capital, and on the other hand, degrees of vulnerability, levels of exposure to environmental risks and hazards, levels of access to environmental resources and amenities, and access to decision-making processes.

Over recent decades, social inequality decreased in many European countries and regions (OECD, 2017). However, since the financial crisis in 2008, Europe's regions have seen growing disparities of social and economic development. Between 2008 and 2012, unemployment increased in four out of five regions in the EU, often most significantly in urban areas. The growth of regional disparities raises concerns of breaking a pattern of long-term convergence. In some regions, the highest unemployment rates are now found in cities, and the number of people at the risk of poverty has increased. While there are improvements in some European cities, many cities still face increases in segregation and polarization patterns (European Commission, 2014a).

Socio-economic status is potentially correlated to access to green areas and inversely correlated to air pollution and environmental noise exposure as demonstrated in a number of studies (Astell-Burt et al., 2014; Hajat et al., 2015). Low-income groups are less likely to have access to green space of high quality, and in that way benefit less from the health gains of contact with nature, whereas at the same time they seem to profit more from such access than their more wealthy counterparts (see e.g. Mitchell and Popham, 2008). In an urban context, such environmental inequalities tend to reveal patterns of socio-spatial disconnectedness and segregation with location-based differences in access to e.g. parks, green cycle routes, and other green/blue infrastructures, different degrees of car dependence due to path dependent habits, distant housing, and proximity to noise, pollution, and waste sites (Marmot et al., 2010; Jensen, 2013).

In this respect, it is also important to notice that the European population is ageing. In 2014, persons aged 65 or over accounted for $18.5 \%$ of the population of the EU-28. Population projections indicate that the EU-28 population will continue to age, with the age category of 65 + having a projected share of $28.7 \%$ in 2080 (Eurostat, 2016). Europeans are also getting overweight at an alarming rate. Increasing prevalence of obesity, even among children, is further reflected in e.g. increased incidence of diabetes (Branca et al., 2007). Physical inactivity, a major determinant of obesity, is typical of present-day urban lifestyles, and an established risk factor for diabetes and cardiovascular diseases. Social isolation is another factor associated with urban living and a risk factor for mental disorders such as depression (Hidaka, 2012; Lambert et al., 2015), which is increasingly contributing to the European burden of disease. Both more physical activity and less isolation are prompted by easy and safe access to greenspaces in cities. Shifts in immigration flows are yet another trend, with people with a very different cultural background entering the European Union. Specifically regarding CES, such new groups may have different needs, cultural practices, and expectations, e.g., of recreation opportunities, landscapes that are considered attractive.

\subsection{Political and policy trends in Europe}

In this subsection, we use Europe as an example to illustrate the political and policy trends of provisioning and management of CES, as well as challenges. Developments in European policy, especially postfinancial crisis, seek to balance economic growth objectives with social and ecological sustainability concerns. Since 1997, sustainable development has been stated as a key objective of European policy. Europe's 2020 growth strategy seeks to deliver smart, sustainable, and inclusive growth. It explicitly addresses the need to reduce health inequalities as a precondition to inclusive growth (European Commission, 2010).

Examples of developments in various policy fields relevant to public health and urban environmental quality and equity are described in Table 1 . It can be seen that environmental health is relevant and is
Table 1

Relevant policies, strategies and regulatory instruments of the EU with regard to ecosystem services and human health and welfare.

\begin{tabular}{|c|c|c|}
\hline $\begin{array}{l}\text { Fields of regulation and } \\
\text { policy }\end{array}$ & $\begin{array}{l}\text { Instruments, milestones, } \\
\text { and initiatives }\end{array}$ & $\begin{array}{l}\text { Linkage to public health } \\
\text { and/or environmental } \\
\text { equity }\end{array}$ \\
\hline Urban & $\begin{array}{l}\text { Unified regional and } \\
\text { urban policy since } 2012 \\
\text { (European Commission, } \\
\text { 2014b) }\end{array}$ & $\begin{array}{l}\text { Cities highlighted as sites } \\
\text { for delivering Europe } \\
2020 \text { targets }\end{array}$ \\
\hline Environment/sustainability & $\begin{array}{l}2030 \text { Agenda for } \\
\text { Sustainable Development } \\
\text { (United Nations, 2015) }\end{array}$ & $\begin{array}{l}\text { Integration of } \\
\text { environmental and social } \\
\text { aspects of sustainability }\end{array}$ \\
\hline Nature and biodiversity & $\begin{array}{l}\text { Communication on Green } \\
\text { Infrastructure and } \\
\text { Natural Capital } 2013 \\
\text { (European Commission, } \\
\text { 2013a) }\end{array}$ & $\begin{array}{l}\text { Health benefits and } \\
\text { aspects of green } \\
\text { infrastructure } \\
\text { highlighted }\end{array}$ \\
\hline Climate/energy & $\begin{array}{l}\text { EU Adaptation Strategy } \\
\text { (European Commission, } \\
\text { 2013c) }\end{array}$ & $\begin{array}{l}\text { Exposure to impacts of } \\
\text { climate change }\end{array}$ \\
\hline \multirow[t]{2}{*}{ Health } & $\begin{array}{l}\text { European Environment } \\
\text { and Health Process, Envi- } \\
\text { ronmental Health Strat- } \\
\text { egy (European } \\
\text { Commission, 2004; WHO, } \\
2018 \text { ) }\end{array}$ & $\begin{array}{l}\text { Recognition of spatial } \\
\text { and temporal variation } \\
\text { in environmental } \\
\text { burdens }\end{array}$ \\
\hline & $\begin{array}{l}\text { WHO Europe Parma Dec- } \\
\text { laration (WHO, 2010) }\end{array}$ & $\begin{array}{l}\text { Special focus on } \\
\text { children's health }\end{array}$ \\
\hline Regional development & $\begin{array}{l}\text { Community-led local } \\
\text { development (CLLD) } \\
\text { (European Commission, } \\
\text { 2014b) }\end{array}$ & $\begin{array}{l}\text { Territorial cohesion, } \\
\text { targeting rural and urban } \\
\text { areas alike }\end{array}$ \\
\hline Transport & $\begin{array}{l}\text { The Transport Health and } \\
\text { Environment } \\
\text { Pan-European Program } \\
\text { (WHO, 2014) }\end{array}$ & $\begin{array}{l}\text { Linkage between } \\
\text { transport, health and } \\
\text { environment }\end{array}$ \\
\hline Disasters & $\begin{array}{l}\text { EU Green Paper on } \\
\text { Insurance of Natural and } \\
\text { Man-made Disasters } \\
2013 \text { (European } \\
\text { Commission, 2013b) }\end{array}$ & $\begin{array}{l}\text { Preventing and } \\
\text { management of } \\
\text { associated health } \\
\text { impacts, including } \\
\text { insurance and } \\
\text { compensation systems }\end{array}$ \\
\hline Research and innovation & $\begin{array}{l}\text { Horizon } 2020 \text { (European } \\
\text { Commission, 2016) }\end{array}$ & $\begin{array}{l}\text { SC1 Health, demographic } \\
\text { change and well-being. } \\
\text { Links to other societal } \\
\text { challenges (e.g. SC } 4 \\
\text { climate and } \\
\text { environment, SC } 2 \text { Food, } \\
\text { water and bioeconomy; } \\
\text { SC } 6 \text { inclusive and } \\
\text { reflexive societies, Smart } \\
\text { Cities and Communities) }\end{array}$ \\
\hline
\end{tabular}

addressed in several fields, besides environmental and health policy (Assmuth and Lyytimäki, 2015). In terms of topics, these fields range from established sectors to challenge-based fields (such as disaster policy), and in terms of types of instruments from general policies to specific initiatives and programs (such as Horizon 2020 (European Commission, 2016)).

Decision-makers in Europe increasingly address the need for public participation and democratic legitimacy for policy and planning processes. This general strive is coupled in the environmental and natural resource area with legal backing through the "greening" of human rights (Boyle, 2012), and the emphasis on procedural environmental rights related to especially transparency and participation of citizens in decision making and planning processes, which was manifested in the 1998 Aarhus Convention (UNECE, 1998). Simultaneously, as part of a conscious development to multi-actor governance, the roles of the public and the private (and the third) sectors have been blurred. These changes in governance may also raise concerns related to deregulation and privatization of ecosystems, which may have consequences for environmental equity through the accompanying privatization of public services (e.g. health care) and public assets, and the reduced 
capacities and coordination of public planning and regulation of environmental issues (Sze and London, 2008).

\section{Functional relationships between CES and the health and well- being of human societies}

Based on the conceptual framework of Hartig et al. (2014), we illustrate the functional relationship between (peri-)urban natural environment's CES and human health and well-being in Fig. 1. The idea that ecosystems contribute to human well-being, including health, is intuitively easy to accept and is in many ways self-evident. At the same time, the precise mechanisms by which they do so, and the scale (individual, community, or society) at which they do so are far from fully understood (Kabisch et al., 2015). Fig. 1 partially illustrates such complexity and inter-relation between different types of activities and health benefits. In addition, the size of the health and welfare benefits generated by different ecosystems, and the different health and welfare services they provide, is not well-known. Moreover, the interplay between environment-related health and welfare factors and other factors, such as genetic, lifestyle, social, and technological factors of health is complex, under researched, and poorly understood. Hence, so far few proven causal connections and feedback loops between health, (peri-)urban dynamics, and environmental policies (from local to European level) affecting ES at different spatial levels have been made. This is especially true when it comes to CES (Daniel et al., 2012). Moreover, contact with "ordinary" urban nature outside the realm of (nature-based) recreation and aesthetic appreciation is not even mentioned in governmental legislation. For example, it is not mentioned in the Common International Classification of Ecosystem Services (CICES 4.3), published by the European Environmental Agency.

To date, there is a substantial amount of epidemiological research showing that easy access to nature, i.e. having nature close to home, is associated with better health, ranging from better self-reported health to lower morbidity and mortality (Hartig et al., 2014; James et al.,
2015; Gascon et al., 2016; van den Bosch and Sang, 2017; Shanahan et al., 2015a; Twohig-Bennett and Jones, 2018; Martens and Nawrot, 2018; Fong et al., 2018). Typically, this research is cross-sectional in nature, i.e. based on observational studies that involve the analysis of data collected from a population, or a representative subset, at one specific point in time. Cross-sectional analysis does not allow strong conclusions regarding the causality of these associations, even though experimental studies have shown that such contacts have at least short-term positive effects on mood, stress level, and cognitive capacities (Hartig et al., 2014; Berto, 2014). On the other hand, inadequate adjustment for confounders in observational studies may lead to too high or low estimates of the health benefits of CES. With lacking specific knowledge of the mechanisms of contribution to health, the risk of misattributing benefits increases. Consequently, an identified health benefit may in fact be due more to other mechanisms and factors. Furthermore, in such epidemiological studies the provision of cultural services is usually defined in crude and general terms. Most studies focus on access to green space, using different operational definitions of green space, as well as maximum distance and minimum surface requirements (Ekkel and de Vries, 2017). It is still unclear by what mechanism which health benefits are generated and for whom, i.e. adaptability of specific urban population groups. On the other hand, specific short-term effects such as stress relief and lower blood pressure from contact with nature (Bowler et al., 2010; Tyrväinen et al., 2014) are difficult to translate to more long-term health outcomes. Hartig et al. (2014) make a plea for longitudinal studies, e.g. cohort studies, to better identify causality in these relationships.

As a consequence, there is a lack of research about which types of nature, or (peri-)urban green infrastructures, are most conducive to improve health and well-being. The indicators, such as distance to nearest public green space or the percentage of green land uses with the residential area, used in studies thus far may be defined too narrowly, neglecting relevant parts of the green infrastructure, or too broadly, including irrelevant components. Likewise, health outcomes may be defined too narrowly, too broadly, or ambiguously. Both types

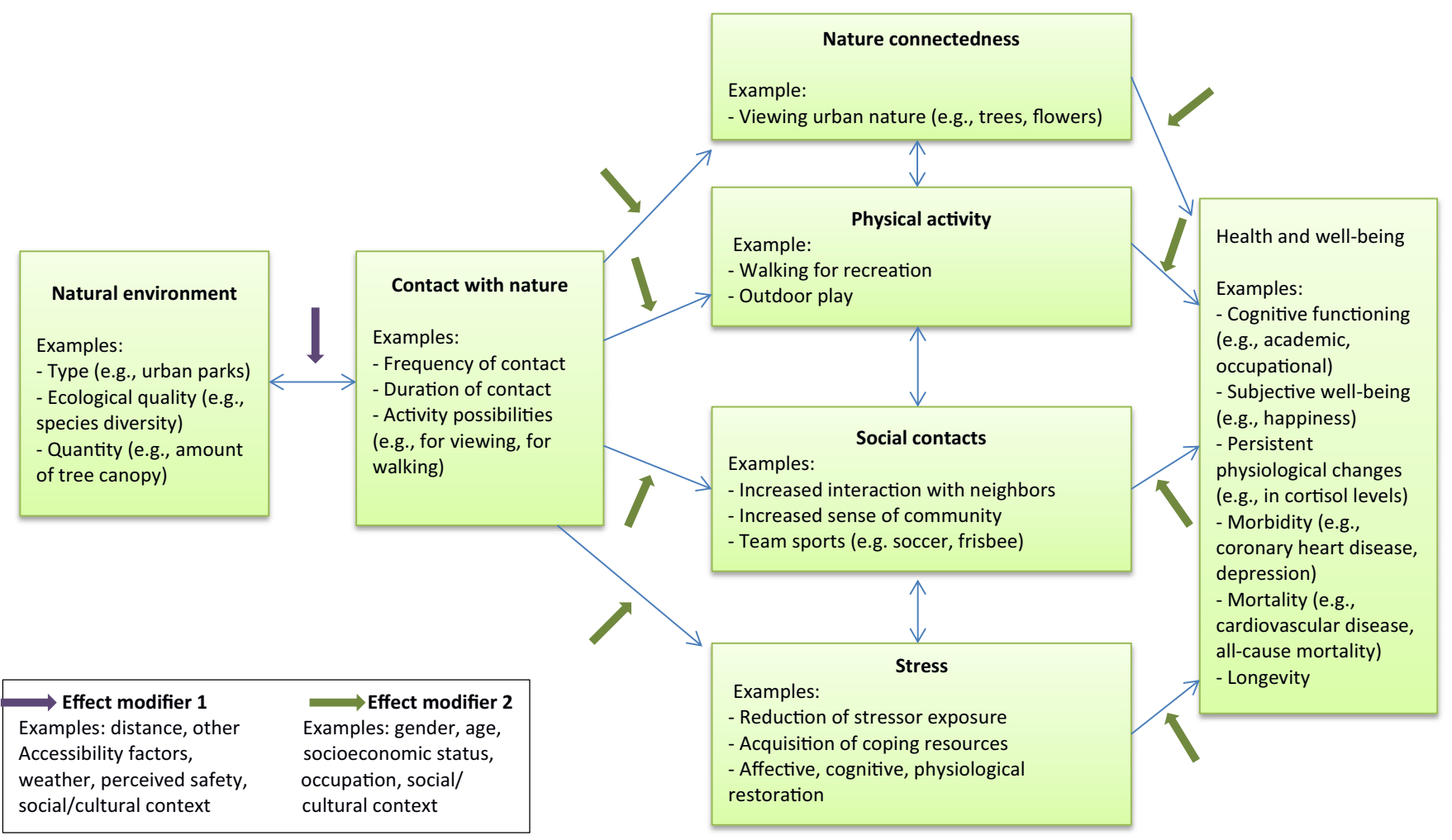

Fig. 1. Functional relationships between (peri-)urban natural environment's cultural ecosystem services and human health. Modified from and based on Hartig et al. (2014). 
of conceptualisations imply that these studies may have underestimated the strength of the association between the provision of CES and health, and thus may have incorrectly estimated benefits, or both (e.g., depending on the population group in question). On the other hand, it is equally important that studies may overestimate the strength of association; mal-estimation can thus involve overrating or underrating of benefits (sometimes both, e.g. regarding various types of benefits and some population groups). While interventions need to be made in short term perspective with the limited information available, a more robust understanding of the mechanisms and outcomes is desirable and needed in order to design and implement policies and interventions with increased effectiveness.

Besides the type of ecosystem, other (perceptions of) characteristics of the areas where people live (natural and other) are likely to be relevant for potential health benefits. For example, if the proposed mechanism is that the ecosystem provides attractive opportunities for physically active forms of outdoor sports and recreation, then certain areas may be more suitable than others. Access, facilities, and amenities present in the area will also be important. Moreover, suitability will depend on the type of activity that the target group likes to perform, and may differ by age group, gender, family, and socioeconomic status, or cultural background. Characteristics that may be relevant are, among others, the (perceived) biodiversity or naturalness of the area, its aesthetic qualities, physical activity and meeting opportunities, security and experienced safety, level of maintenance, integration in the surrounding urban environment, accessibility (physical as well as regulative), and the peace and quiet that the area offers (de Vries, 2010; Hartig et al., 2014). Besides more detailed data on and theoretical understanding of the characteristics of the ecosystem, also better information on the actual exposure to or use of the ecosystem service may help to establish the plausibility of the observed associations being causal in nature. As mentioned in the introduction, many CES require contact with the ecosystem for its services to be enjoyed. To the extent that the association between the provision or supply of ES and health can be shown to be mediated by actual contact with or visit of the ecosystem, a causal interpretation becomes more plausible. Finally, studies aimed at investigating the health benefits of green areas need to account for confounding factors, such as socio-economic status, gender, age, and ethnicity.

\section{Current research and key topical research questions for a new re- search agenda}

\subsection{Mechanisms and outcomes: How does the use of CES affect health and well-being?}

Although the biophilia hypothesis has been affirmed in many empirical studies, the causal mechanisms are not yet clear (Sandifer et al., 2015); they also cannot be, as they vary depending on the object of attention or affection (e.g., animals; plants; nature as a whole) and on the form or level of biophilia - neurological, behavioural, cultural, aesthetic, ethical. Though different facets, these are not mutually exclusive. For example, attention to nature is on some level evolutionarily hard-wired in our genes and brains as a necessity, but also depends on upbringing and education (Thompson et al., 2008). Thus, it is challenging even to define biophilia, let alone measure it as a health factor. The question of the causality of observed relationships is in any case closely related to that of the operating mechanisms, like with other types of health determinants and etiological inference.

In cross-sectional studies, it is important to exclude alternative explanations as much as possible (Markevych et al., 2017). In many studies, attention has been paid to socioeconomic status, since this is related to access to nature on the one hand and to health on the other. The levels of urbanity or population density at various scales are other relevant characteristics, as are the cultural and demographic heterogeneity of the population and the characteristics of urban design in areas of little/high use. Both a high population density and differences in life styles may contribute to social conflicts, resulting in lower residential satisfaction and higher stress levels. On the other hand, population density is strongly inversely related to access to nature and positively related to air pollution and noise exposure. Moreover, the effectiveness of visits to green space lowering stress may depend on how intensively the green area is used. This begs the question whether it is access to green space in general or access to private or quiet peaceful green space that is most relevant. This feeds back into the question of the best indicators for the provision of CES: is it the absolute amount of green space, or perhaps the amount and quality, including accessibility, of green space per capita that matters most? Answers to such questions have important practical implications. Furthermore, specification of the metrics of both the contact with nature as well as the health outcomes is important, as far as proof of effectiveness is desired.

Another issue is the question of the extent and diversity of the health benefits that result from making use of CES. Obviously, the net benefit of ES depends on the magnitude of their effects on specific health outcomes, and the number of outcomes affected by the use of the services. As mentioned in the introduction, one of the reasons to introduce the concept of ES was to make the benefits that people and society derive from ecosystems more clear, conceptualized, visible, and, if possible, also measurable, in terms of monetary or non-monetary value. Until now, this has proven to be quite difficult to do in a robust way, partly because of the multiplicity of values and the often indirect ways they are accrued. This depends also on the answers to the previous questions regarding causality and effective components of the green infrastructure. However, an exploratory study by KPMG (2012) showed that when it comes to mental health, the economic benefits will not be primarily in terms of the reduced costs of health care consumption, but in terms of reduced cost for sick leave and increased economic productivity (through work).

Who are the beneficiaries? This is another key policy question, related to the type and scale of benefits. For instance, while some health benefits of nature-based interventions may not be sizeable or even measurable in the general population, they may be very important for particular groups such as infants or elderly, or those already disadvantaged (e.g. poor people, the obese, or the chronically ill). A related key question is over what period of time beneficiaries are factored in - if over many generations, it may radically alter benefit calculations especially in the case of lagged benefits and other non-linear long-term effects from nature, e.g., those subject to a threshold. Inter-generational distribution of benefits (and of costs and burdens) is relevant too. However, the discount rate of nature, particularly cultural assets, and health, are difficult to specify.

As already mentioned, there are indications that CES are especially relevant for mental health (Van den Berg et al., 2015; Mitchell et al., 2015) and social networks and cohesion (Weinstein et al., 2015). Some studies have also linked access to or use of green space to improved physical health such as lower risk of cardiovascular diseases and diabetes (Richardson et al., 2013; Tamosiunas et al., 2014). This could be explained by increased physical activity due to the vicinity of green space, providing urban spaces designed for e.g. running, cycling, and ball games, which may interact with other relevant mechanisms. For example, improved mental health may be reflected in physical health: clinical research has identified many links between mental and physical health on a physiological and biochemical level (see e.g. Carney et al., 2005; Thurston et al., 2013).

Once it becomes clear which components of the (peri-)urban green infrastructure are relevant for which mechanism, it will be possible to look for potential synergies between different mechanisms and to identify to what extent the same components play a positive role in these different mechanisms. If the mechanisms interfere (conflict or compete) with each other, trade-offs can be made based on which mechanism or outcome is considered more beneficial. In local and regional applications of nature-based functions of the green infrastructure, 
other factors than those directly related to health will come into play, e.g., providing regulating ES through water management (climate adaptation). Such co-benefits of nature protection and care are potentially key to interventions and are emphasized e.g. by the EC, but can be hard to assess and thus prone to over- as well as underestimation. Consequently, it will be important to clarify possible synergies and tradeoffs with such other functions. In addition, the costs of developing, altering, and maintaining the green infrastructure are relevant for performing social cost-benefit analyses in this context. Without taking the multi-functionality of the green infrastructure into account, its costs may easily outweigh isolated benefits. This multi-functionality is a presumed advantage of NBS (Eggermont et al., 2015). However, it is important to assess it in an adequate way. Especially for CES, instruments that have been developed are limited to recreational ecosystem services mainly (Schägner et al., 2018; Hermes et al., 2018), and therefore the knowledge and instrumentsneeded for assessment are still largely lacking.

In order to deepen the understanding of the contributions of CES to public health, we suggest addressing the following general questions:

- Which types of CES are best suited to generate which types of health benefit, and for whom? Or, starting from health benefits, what is needed by whom and which CES may be of use?

- What are the underlying psychological, social, physiological and molecular mechanisms involved in generating these health benefits for this population segment?

- What type of green infrastructure and spaces, with which characteristics, will provide the required CES in an optimal way to that population segment? For example, in terms of spatial structure, accessibility, size of area, type of vegetation or ecological community, amenities, maintenance?

- Can we attach a monetary or non-monetary value to those benefits? Can they be valuated, and how and with what limitations and caveats?

- To what extent do synergies rather than trade-offs exist when combining different ecosystem services within a single ecosystem or green infrastructure, specifically with regard to health benefits generated (possibly also for different population segments?

- To what extent do synergies rather than trade-offs exist when combining health-producing ES with other ES, i.e. services not directly aimed at improving health and well-being within the same ecosystem or green infrastructure including key ES for health such as food produced elsewhere)?

- What are the relationships between the functions of urban green structures and other structures, notably 'grey' infrastructures (e.g., for water, air and solids management, energy prosumption, mobility and communication) in promoting health?

- What are the interactions of health care and social support systems with nature protection and management (including e.g. urban gardening), specifically in providing cultural services for health and well-being?

\subsection{Mapping and modelling of CES: Supply, demand and use}

Besides increasing knowledge on which types of ecosystems provide which particular CES and how important these are with regard to public health (see e.g. Oosterbroek et al., 2016), spatially explicit knowledge on the supply of such CES is relevant. Paralleling that, users or "consumers" usually have to establish physical contact with one or several ecosystems to enjoy this type of service, making the spatial distribution of the demand or need for these services also relevant (Bagstad et al., 2014). Combined supply and demand information together offers inputs for maps and models predicting local use and deficits of available services. Data on actual use give even more accurate information on the extent to which the potential benefits are realized, and usually also on what this depends on. The relevance of taking demand explicitly into account was acknowledged by Paracchini et al. (2014). Their study was part of a larger effort to set up tools and methods for the spatially explicit evaluation of ES in support of the Biodiversity Strategy 2020, the MAES project: Mapping and Assessment of Ecosystems and their Services. The study focuses on outdoor recreation as an important CES at the European scale.

Quite different assumptions, for example regarding the size of buffer of ecosystem that affects health, have been made in studies. Paracchini et al. (2014) make a distinction between close-to-home trips (maximum $8 \mathrm{~km}$ distance) and day trips (maximum $80 \mathrm{~km}$ distance). In the literature on nearby nature and health, distances tend to be (much) smaller: $3 \mathrm{~km}$ is already considered a large distance and distances of $500 \mathrm{~m}$ or less are common, in particular in urban areas where cycling and walking are valued and integrated in urban mobility. Another issue is the minimum size of areas to be included. Annerstedt van den Bosch et al. (2015) suggest an accessibility indicator based on having at least 1 ha within $300 \mathrm{~m}$ as a criterion. However, even smaller natural elements such as street trees and pocket parks have been suggested to provide benefits (Taylor et al., 2015). A third issue is that in the nature and health literature also contact without a recreational motive is considered relevant (Hartig et al., 2014). Recreational visits are only one of many ways people encounter nature, and e.g. cycle tracks passing through green spaces promote urban cycle practices (Jensen, 2013). Furthermore, until now environmental indicators for CES have primarily focused on access to green space. Recently studies begin to show that access to blue space (fresh and salt water surfaces) is also of importance for human health and well-being (Foley and Kistemann, 2015). Finally, access is not defined only by distance (and route and means of transport), but involves obstacles such as fencing, social or legal hindrances and support, and the ability of people to enter the ecosystem, especially among some groups such as children and the elderly (Laatikainen et al., 2015, 2017; Assmuth et al., 2017).

To improve the modelling and mapping of the demand for and supply and actual use of CES relevant with regard to public health, we suggest that:

- Ecosystems are mapped according to their suitability to provide a specific sets of CES (defining the potential service). This mapping will aid policy makers, planners, and researchers in decision making, planning, and scientific activities.

- The demand for specific CES is mapped, including specific demands regarding the way the service is best provided.

- Differences in access to CES between population segments are mapped, especially with regard to socioeconomic status, ethnicity and/or cultural background.

- Actual use (the service realized) is modelled (and mapped), bearing in mind that a) use may be based on the set of services offered by the ecosystem, rather than on a specific service, b) access to the service is an important consideration, c) use needs not to be limited to purposeful (recreational) visits; visual contact through window or exposure during daily commuting may be all that is required in some cases, d) use of the servicemay vary according to season and climate, and e) different population groups (age, gender, ethnicity, levels of education and income) largely vary considerably in their use of the service.

- Social value mapping, a subjective way of mapping the suitability of ecosystems to offer certain services, may be used as a relatively new spatially explicit data gathering tool. Value perceptions and also more objective values may differ between population segments, e.g. between ill and healthy individuals.

- Digital experience sampling methods (including remote sensing and GPS-data) may be used as a new spatially explicit data gathering tool. Depending on the way data are gathered, this tool may also offer information on contact/use (time sampling). 
The level of detail for the application of models and for the collection of data has to be context-specific and support decision making, rather than constrain it. This is an important consideration, as the resolution and detail in place-based and also many other types of data are increasing. Detail in both models and data can distract from conceiving and conveying the whole picture, and may add unnecessary complexity that counteracts needed simplification.

\subsection{Environmental equity and socioeconomic health differences}

Until now, the field of urban environmental equity is dominated by studies focusing on single challenges and how they relate to sociospatial inequalities. Furthermore, research has been mainly conducted in the context of air quality, soils, and noise, as well as disaster-type natural and anthropogenic hazards, including floods, hurricanes, heat and industrial accidents. Environmental inequity more generally and in itself can already be considered undesirable. Moreover, if environmentally adverse conditions go together with socioeconomic deprivation in producing health deficits, this is even more clearly the case (Banzhaf et al., 2014). This leads to the following questions. Where does socioeconomic deprivation co-occur with environmentally adverse conditions, resulting in a low access to ecosystems offering health-related CES? To what extent are socioeconomic and sociodemographic status and environmental quality of the residential areas associated? And if they are, to what extent are socioeconomic health differences mediated by differences in this environmental quality, or to what extent the reverse is the case: environmental quality is shaped by socio-economic and related health differences? A study by Mitchell and Popham (2008) suggests that the latter may be the case. In England, socioeconomic differences in mortality were smaller within the category of green neighbourhoods than within the category of less green neighbourhoods. More recently, Mitchell et al. (2015) observed a similar association for mental health in a pan-European study. These results are consistent with other studies suggesting that access to green space is especially important for the health and well-being of socioeconomically deprived people, as well as that of the young and the elderly. As a consequence of these associations, can socioeconomic health differences be lessened by increasing access to nature in socioeconomically deprived areas?

In order to deepen the understanding of the contribution of inequity in the provision of CES to socioeconomic health disparities, we suggest addressing the following research questions:

- To what extent are socioeconomic health disparities mediated by differences in access to CES? Could socioeconomic health disparities be reduced by reducing associated inequities in environmental conditions?

- How are environmental inequities produced, and which of the contributing factors offer policy makers the best opportunities to reduce them? And how does environmental inequality differ across population groups, i.e. according to level of education, income, age, gender, social capital, or ethnicity?

- What differences and similarities do the European cities have with cities in other regions, and what are the implications for better ensuring health benefits from CES?

- In which cases and for what reasons do other injustices and inequities compete with and even trump environmental injustices and inequities, and what does this mean for priority-setting and social choices?

4.4. Knowledge on action: Institutions, norms and policies, strategies and plans, governance and collaboration, technologies and communication, and other capabilities and prerequisites of interventions

A crucial complement to the above topical areas of research is composed of the many disciplines and applied fields of activity that directly address interventions. This area is inherently and self-evidently crucial for action to promote health and other desired ends.

The under-representation of R\&D in this broad topical area has to do with e.g. the following linked problems: a) health and environmental research has been despite developments toward multi-disciplinarity traditionally focused on natural scientific aspects, grasping health and nature from biophysical (or biomedical) angles; b) this is related to a focus on technological, e.g. "pill-type" solutions (with analogies in environmental and urban engineering); c) these are coupled to a preoccupation with data and models and associated premiums on exactitude; d) especially in health research, the necessary emphasis on evidence has led to a dominance of quantification, deterministic models and statistical proof; e) there is a general narrow view of scientific explanation, prediction and experimentation based on outdated positivist ideas; f) while there are viable action-oriented traditions in intervention studies, these are constrained by the increased complexity of problems and solutions; g) even in socio-economic sciences the need for detachment of research tends to sidestep an orientation to action; h) specifically, political sciences are shunned in an attempt to retain illusions of value-free science, due to the misconception that to study politics means one is political and unscientific (this is seen e.g. in the scientific advisory bodies on health, imputing analyses out of fear of politicization).

To solve these problems, the following approaches can be suggested:

- With regard to CES and human health, the viability of many conceivable culture-based and culture-generating interventions and actions, traditional or innovative, needs to be studied.

- Needs, obstacles, and facilitating processes and associated transitions and path dependencies need to be clarified. Time scales and other key features of interventions need to be delineated. The consequences need to be assessed. Synergies and trade-offs need to be accounted for. Finally, conflicting and consensual values need to be traced. This will require new methods of policy and strategic (options) analyses, including open-ended, anticipatory and value-based approaches where answers are framed in a pluralistic and heuristic manner, building on various types of knowledge, and relaxing normative goals of definite answers.

- Communication among publics and actors and its links with perceptions and behaviours of health promotion is a research priority. A key question here is, how can people be aided to articulate their needs and capabilities and assisted to beneficial (at least no-regret) action, with particular reference to personalized medicine and culture.

- In urban settings, participatory research is needed in interventions devised and deployed based on negotiated and adaptive multi-actor (including multi-sector) governance, and embedded in existing democratic and inclusive planning and decision making procedures. The appropriate balance between top-down and bottom-up interventions, including community-based experiments in city planning, is an important topic in such participatory research, in order to successfully combine experiments with systematic follow-up, evaluation and steering for social learning.

- Particular needs and opportunities of specific groups of people among urban residents and others (including those engaged with nature on leisure), such as disadvantaged groups, should be studied; on the other hand, such groups and their interaction and collaboration as a human resource and a vehicle for social learning should be given great attention.

- The integration of market and other voluntary mechanisms and incentives with regulatory steering for interventions is a research priority, based on a broader understanding of environmental and health values and of natural and human capital.

- The interaction between knowledge generation (from research and other activities such as monitoring and follow-up), interpretation, brokering and interventions is a priority area, and should in particular address the balancing of evidence with precautionary and conjectural 
"feel-good" solutions to enable adequate as well as acceptable care, and citizen science/assessment or other forms of public engagement.

\section{Methodologies and R\&D approaches}

European Commission's present Horizon 2020 calls with regard to NBS, specifically in the context of urban development, focus more on innovation than on research; they call for large scale applications with front runner and follower cities. In the other parts of the program more Research \& Innovation (R\&I) Actions are included, especially in relation to health, but these seldom explicitly and broadly address environmental (or urban) aspects and issues. Thus, the environmental health benefits of nature as areas for research and innovation presently fall through the gaps. However, the previous sections show that there are still a lot of open questions as well as promising opportunities in how to exploit the potential health benefits of an urban green infrastructure in an effective and efficient way. Whereas the previous sections have highlighted topical research questions and innovations, here we focus particularly on the methodological challenges involved.

At present, most research on the benefits of consuming CES for health and well-being is focused on access and is cross-sectional in nature (Hartig et al., 2014; Markevych et al., 2017). Longitudinal studies as well as natural experiments and laboratory studies are needed to complement these cross-sectional studies, so that the causality of the observed associations may be more firmly established.

In the health research sector there is a tradition of conducting longterm cohort studies. Whenever possible, existing longitudinal health data should be used in secondary data analyses. European research on the health effects of air pollution, e.g. the recent ESCAPE project (Beelen et al., 2014), has demonstrated the cost-effectiveness of the approach (see also Fleming et al., 2014). Since these longitudinal datasets usually do not contain data on the local supply (nor use or demand) of CES, this type of supply data has to be added. This presupposes that such data are available and indicator values are determined in a consistent way over time (backward long-term monitoring). Due to the lack of data, their replacement with proxies becomes an important option. Its success depends on the models used, and on our understanding of the system, including mechanistic information of the ecosystem as well as health and socioeconomic systems. On the health side, registry data, such as data from health insurance companies and electronic patient records will offer opportunities.

In addition, ongoing or new longitudinal health data collection efforts may be somewhat adapted to include data on the (perceived) supply and/or use/demand of CES, including quality and suitability aspects, and possible mediators (physical activity, stress, and social cohesion).

Vice versa, data collection primarily aimed at the use of CES may be extended to also include information on health aspects. In that case it is important to look not only at the use of the services of a specific ecosystem, but (also) at the use of such services over all ecosystems within the maximum distance that an individual can travel (i.e., action radius). Preferably, spatially explicit information on what service of which ecosystem is used and how often should be recorded. This will help in determining the contribution of specific ES, e.g., at the place where people live, schools they attend or places they work. At the same time an appropriate balance between specificity of data (requiring extensive research and monitoring) and its generalizability should be found. Longitudinal health data from longer-term cohorts or shorter-term panel studies would enable mechanistic analyses. For example, as potential mechanistic explanations for observed health benefits in relation to green space, reduced stress levels, and enhanced immune function are currently discussed (see e.g. Kuo, 2015). These hypotheses could be tested in cohorts with available bio-samples.

With regard to natural experiments, environmental interventions that substantially change the local supply of CES are of interest. Changes that do not considerably alter the local supply situation (from the perspective of a citizen) are unlikely to result in substantial health effects. Since such large-scale changes are unlikely to take place just for the purpose of scientific research, timing is important. Sound natural experiments should start with pre-measurements before the changes take part and include several post-measurements, preferably outlasting the environmental intervention itself by several years. Delays or changes in the execution of the intervention itself are to be expected. This requires an uncommonly flexible way of research funding: quick startup with a rather open ending. In health research, the efficiency and risks of experiments and interventions are routinely analysed (using systematic literature review and meta-analysis methods) and the quality of evidence on them is extensively evaluated. Their advanced methods developed can also be utilized in the area of nature and health.

The mapping of CES is still in its infancy. Furthermore, predominant methodologies in the context of topics related to urban environmental quality and equity comprise the mapping of distributions of hazards and health risks (heat, flood, air pollutants (see e.g. Franck et al., 2014), and noise). These typically combine hazard occurrence with socio-economic indicators (as in vulnerability analyses), household surveys and other social science methods for analyzing perceptions and coping capacities. Also, these methodologies are mostly indicator- and indices-based or case study approaches and are limited in reflecting the complexity of urban environmental quality and equity.

Methods need to allow for both the case-based investigations of urban environmental quality and equity as well as the generation of transferable results that go beyond context-specific indicatorapproaches, thus reflecting the broader picture (in space and time). Moreover, it is of key importance for researchers, planners, policy analysts, and decision makers to examine the development of information and knowledge that appear understandable and is aimed at specific target-groups, including, e.g., decision-support tools. These tasks also require studies of perceptions of (health and environmental) benefits, risks and impacts, and of the aspirations and motivations of citizens, to be qualitatively as well as quantitatively modelled. In addition, the conceptual problems, the inter linkages of the use of different CES and other urban wellbeing and health dynamics need to be addressed.

Models on the use of cultural as well as other ES may generate output that can be used in establishing and estimating health effects, especially since data on actual use are often lacking. However, the considerations discussed in the section on mapping also have implications for the suitability of the outcomes for such purposes. Additionally, models developed in the environmental research domain tend to focus on the use of specific ecosystem areas aggregated over users or visitors, sometimes including tourists. It is also important to account all the ecosystem areas that an individual visits, and aggregate the associated use and benefits. The same model might be able to generate both types of outcomes. With regard to making use of the local supply of services being offered, it should be pointed out that individuals that are faced with the same local supply situation may not respond to it in the same way, due to differences in preferences and nature-orientedness, in restrictions at the individual or household level, or a combination of both. Increasingly, modelling approaches are looking to also define user characteristics as well as environmental characteristics (Jones et al., 2016). Closer cooperation between environmental and social scientists may help to develop multifunctional models, and more unified socio-ecological theories (cf. Reis et al., 2013).

A key issue for developing models of CES use in urban environments and the associated benefits to health is the almost complete lack of the underlying data and dose-response relationships required to adequately construct the models at the moment. For an overview and critique of common conceptualization of dose-response models, see e.g. Shanahan et al. (2015b). Considerable primary data collection is still required before adequate models of uses and benefits can be created. The measurement of the primary data, i.e. doses, needs to move beyond simplistic measures that are currently used in the literature (Shanahan 
et al., 2015b). Even with recent research progresses (e.g. Shanahan et al., 2016; Cox et al., 2017, 2018), there is substantial scope for developing semi-quantitative and semi-qualitative conceptual frameworks and modelling/mapping both the potential supply of CES and the potential demand for and use of them. Pioneering work on this issue is currently on-going in Manchester, Birmingham, and Sheffield, under UK's Natural Environment Research Council (NERC) Valuing Nature Programme in Urban Areas. On a global scale there is the Biophilic Cities Network.

The development of indicators for the suitability of ecosystems to offer certain cultural services, in addition to their accessibility, has been quite limited. Objective assessments tend to require audits, making large-scale studies involving many participants, each with their own residential environment, labour intensive, and therefore costly. However, GIS- and remote sensing data, including public participatory GIS (PP-GIS) and the use of mobile phone apps, are becoming increasingly detailed and versatile, and offer new opportunities for assessing this type of suitability at a large scale in cheaper ways. Big data, e.g., regarding the whereabouts of cell phone owners, may also offer new possibilities to gather information on actual use of ES.

Transferring lessons between and from cities in the non-European context is crucial and needs to be part of the research agenda. Many cities in Latin America, Asia, and Africa are highly unequal in terms of socio-spatial differentiation and it is worth comparing Europe's urban problems with those of other continents where socio-spatial segregation has different reasons, trajectories, and outcomes and involves different environmental quality, health, and equity concerns. Since the topic is timely and calls for long-term solutions, the research agenda too should be long-term. It may also however benefit from a close link with experiments, demonstrations and other work on practical solutions, including especially innovative solutions for governance and social learning.

\section{Conclusions}

Facing increasing pressures and competition, many urban areas are increasingly proactive in developing solutions to sustainability challenges. Pursuing or starting to pursue transitions toward e.g. post-carbon or smart cities, the focus most often is on technological solutions, usually targeting single problems. Nature-based solutions can potentially be multifunctional, providing several types of benefits at the same time. One of the seven R\&I Actions recommended by the expert group on nature-based solutions and re-naturing cities to be taken forward by the European Commission and Member States is that for improving well-being in urban areas (European Union, 2015). In this research agenda, environmental equity in terms of access to CES, and the role of environmental equity with regard to socioeconomic health disparities should also be included. The role of ecosystem dis-services should also be taken into account in this agenda (e.g. street-tree pollen and allergies).

Eradicating or alleviating environmental inequities poses challenges to urban planning, policy implementation, and inclusive economic development. Research on such issues is still scarce (Gelormino et al. 2015). The proposed urban environmental quality and equity research should help decision-makers at local, national and continental levels to identify problematic situations, accommodate quality and equity needs in planning efforts and to design integrated policies to tackle related problems. Furthermore, considering the direct relevance to answering several challenges and targets listed in the United Nations' SDGs, the actions and approaches proposed in this paper are globally relevant.

We have identified the need for initiating research on the following aspects of urban environmental quality and equity:

(1) Evaluating the association of CES with indicators of mental and physical health in different regions and population subgroups, and assessing the total impact.
(2) Addressing CES and gains for health and wellbeing in the perspectives of increasing or mitigating equity.

(3) Identifying mechanisms between health/well-being and access to/use of urban green and blue spaces, their relative importance.

(4) Evaluating the ecosystem or green (and blue) infrastructure characteristics and conditions that are responsible for the health and wellbeing effects of CESs.

(5) Exploring methodological innovations and big data (e.g. data gathering, indicator development, and modelling) to develop a solid knowledge base on the relationships between ecosystems or urban green infrastructure, CES, and the contribution the latter may make to environmental quality, and in that way to public health.

(6) Identifying underlying causes and drivers of low environmental quality, specifically low access to CES, and large inequities in access, including global and local environmental change and related impacts, as well as governance approaches (legal rights, policy processes, goals and strategies, participation of citizens and urban stakeholders).

The potential research agenda is broad, and extends the capacities of individual research organizations. We see the need and also several opportunities for a broader research effort, encompassing various types of field study. Such opportunities can be identified based on previous research and capacity-building, on the resultant methodological, theoretical and empirical insights, and on the greatly increased interest and activity of citizens and societies in nature-based health solutions.

The broader research effort on urban environmental quality and inequity extends over various societal challenges, including e.g. health, demographic change, and wellbeing issues, and should be further explored through a combination of calls under the Horizon 2020 program as well as the opportunities offered by other instruments from local to global levels. Overall, the proposed research agenda should adopt a broad, interdisciplinary, and transdisciplinary approach based on a mixture of environmental, natural, medical and social science disciplines and with a long-term temporal horizon, including both historical and future trajectories (Lang et al., 2012).

\section{Acknowledgements}

All authors, except T. Lanki, received internal funding from Partnership for European Environmental Research (PEER), where their employers are part of. X. Chen acknowledges funding from the Strategic Institute (SIS) programme of the Research Council of Norway (grant no. 160022/F40) for the URBAN SIS project. A. Jensen was supported by the NordicWelfAir Project (project no. 75007: Understanding the link between Air pollution and Distribution of related Health Impacts and Welfare in the Nordic countries) funded by NordForsk's Nordic Programme on Health and Welfare. O. Hertel was supported by the BERTHA Project (project no. 27864: Big Data Center for Environment and Health) funded by Novo Nordic Foundation under 812 Challenge Programme: Big Data in BioMedicine. The contributions of J. Dick, L. Jones. L. Maskell, L. Norton, and S. Reis were supported by the Natural Environment Research Council award number NE/R016429/1 as part of the UK-SCaPE programme delivering UK National Capability.

\section{References}

Andermann, A., Pang, T., Newton, J.N., Davis, A., Panisset, U., 2016. Evidence for health I: producing evidence for improving health and reducing inequities. Health Res. Policy Syst. 14, 18.

Andersson, E., Tengö, M., McPhearson, T., Kremer, P., 2015. Cultural ecosystem services as a gateway for improving urban sustainability. Ecosyst. Serv. 12, 165-168.

Annerstedt van den Bosch, M., Mudu, P., Uscila, V., Barrdahl, M., Kulinkina, A., Staatsen, B., et al., 2015. Development of an urban green space indicator and the public health rationale. Scand. J. Public Health 44 (2), 159-167. 
Antonovsky, A., 1996. The salutogenic model as a theory to guide health promotion. Health Promot. Int. 11 (1), 11-18.

Assmuth, T., Lyytimäki, J., 2015. Co-constructing inclusive knowledge in converging fields: environmental and health care. Environ. Sci. Pol. 51, 338-351.

Assmuth, T., Hellgren, D., Kopperoinen, L., Paloniemi, R., 2017. Fair Blue Urbanism: Demands, Obstacles, Opportunities and Knowledge Needs for Just Recreation by Helsinki Metropolitan Area Waters. Mimeo.

Astell-Burt, T., Feng, X., Mavoa, S., Badland, H.M., Giles-Corti, B., 2014. Do low-income neighbourhoods have the least green space? A cross-sectional study of Australia's most populous cities. BMC Public Health 14, 292.

Bagstad, K.J., Villa, F., Batker, D., Harrison-Cox, J., Voigt, B., Johnson, G.W., 2014. From theoretical to actual ecosystem services: mapping beneficiaries and spatial flows in ecosystem service assessments. Ecol. Soc. 19 (2), 64.

Banzhaf, E., De la Barrera, F., Kindler, A., Reyes-Paecke, S., Schlink, U., Welz, J., Kabisch, S. 2014. A conceptual framework for integrated analysis of environmental quality and quality of life. Ecol. Indic. 45, 664-668.

Beelen, R., Raaschou-Nielsen, O., Stafoggia, M., Andersen, Z.J., Weinmayr, G., Hoffmann, B., et al., 2014. Effects of long-term exposure to air pollution on natural-cause mortality: an analysis of 22 European cohorts within the multicentre ESCAPE project. Lancet 383, 785-795.

Berto, R., 2014. The role of nature in coping with psycho-physiological stress: a literature review on restorativeness. Behav. Sci. 4 (4), 394-409.

Bertrand, N., de Haas, W., Jensen, A., Krellenberg, K., Peltonen, L., Seifert-Dähnn, I., 2015. Urban Environmental Equality (Position paper, Doc DBM36-7).

Bowler, D.E., Buyung-Ali, L.M., Knight, T.M., Pullin, A.S., 2010. A systematic review of evidence for the added benefits to health of exposure to natural environments. BMC Public Health 10, 456.

Boyle, A., 2012. Human rights and the environment: where next? Eur. J. Int. Law 23 (3), 613-642.

Branca, F., Nikogosian, H., Lobstein, T., 2007. The Challenge of Obesity in the WHO European Region and the Strategies for Response: Summary. World Health Organization.

Carney, R.M., Freedland, K.E., Veith, R.C., 2005. Depression, the autonomic nervous system, and coronary heart disease. Psychosom. Med. 67 (Suppl. 1), S29-S33.

Charron, D.F., 2012. Ecohealth: origins and approach. In: Charron, D.F. (Ed.), Ecohealth Research in Practice. Springer, pp. 1-30.

Checker, M., 2011. Wiped out of the "Greenwave": environmental gentrification and the paradoxical politics of urban sustainability. City Soc. 23, 210-229.

Cox, D.T., Shanahan, D.F., Hudson, H.L., Plummer, K.E., Siriwardena, G.M., Fuller, R.A., Anderson, K., Hancock, S., Gaston, K.J., 2017. Doses of neighborhood nature: the benefits for mental health of living with nature. Bioscience 67 (2), 147-155.

Cox, D.T., Shanahan, D.F., Hudson, H.L., Fuller, R.A., Gaston, K.J., 2018. The impact of urbanisation on nature dose and the implications for human health. Landsc. Urban Plan. 179, 72-80.

Daniel, T.C., Muhar, A., Arnberger, A., Aznar, O., Boyd, J.W., Chan, et al., 2012. Contributions of cultural services to the ecosystem services agenda. Proc. Natl. Acad. Sci. 109 (23), 8812-8819.

de Vries, S., 2010. Nearby nature and human health; looking at mechanisms and their implications. In: Thompson, Ward, Aspinall, Bell (Eds.), Innovative Approaches to Researching Landscape and Health; Open Space: People Space 2. Routledge, Oxon/ New York, pp. 77-96.

Degeling, C., Johnson, J., Kerridge, I., Wilson, A., Ward, M., Stewart, C., Gilbert, G., 2015. Implementing a One Health approach to emerging infectious disease: reflections on the socio-political, ethical and legal dimensions. BMC Public Health 15, 1307.

Eggermont, H., Balian, E., Azevedo, J.M.N., Beumer, V., Brodin, T., Claudet, J., Fady, B., Grube, M., Keune, H., Lamarque, P., Reuter, K., Smith, M., van Ham, C., Weisser W.W., Le Roux, X., 2015. Nature-based solutions: new influence for environmental management and research in Europe. GAIA 24 (4), 243-248.

Ekkel, E.D., de Vries, S., 2017. Nearby green space and human health: evaluating accessibility metrics. Landsc. Urban Plan. 157, 214-220.

European Commission, 2004. The European Environment \& Health Action Plan 20042010. SEC(2004) 729. European Commission, Brussels.

European Commission, 2010. Europe 2020: A Strategy for Smart, Sustainable and Inclusive Growth. COM (2010) 2020 Final. 35 p. European Commission, Brussels https://eur-lex.europa.eu/LexUriServ/LexUriServ.do?uri=COM:2010:2020:FIN: EN:PDF.

European Commission, 2013a. Communication From the Commission to the European Parliament, the Council, the European Economic and Social Committee and the Committee of the Regions on Green Infrastructure (GI) - Enhancing Europe's Natural Capital (Brussels, 6.5.2013. COM(2013) 249 final. 11 p).

European Commission, 2013b. GREEN PAPER on the Insurance of Natural and Man-Made Disasters. (Strasbourg, EC 16.4.2013. COM(2013) 213 final. 21 p). http://eur-lex.europa.eu/legal-content/EN/TXT/PDF/?uri=CELEX:52013DC0213\&from=EN.

European Commission, 2013c. An EU Strategy on adaptation to climate change. COM (2013) 216 FinalEuropean Commission, Brussels.

European Commission, 2014a. Promoting development and good governance in EU regions and cities. Sixth Report on Economic, Social and Territorial Cohesion Investment for Jobs and Growth. European Commission, Brussels.

European Commission, 2014b. Community-Led Local Development, Cohesion Policy 2014-2020. accessed on. http://ec.europa.eu/regional_policy/sources/docgener/ informat/2014/community_en.pdf, Accessed date: 10 April 2018.

European Commission, 2015. Towards an EU Research and Innovation Policy Agenda for Nature-Based Solutions \& Re-Naturing Cities. European Commission, Brussels.

European Commission, 2016. Horizon 2020: The EU Framework Programme for Research and Innovation. (URL). https://ec.europa.eu/programmes/horizon2020/, Accessed date: 5 December 2016.
Eurostat, 2016. Home: Eurostat. (URL). http://ec.europa.eu/eurostat, Accessed date: 5 December 2016

Fleming, L.E., Haines, A., Golding, B., Kessel, A., Cichowska, A., Sabel, C.E., et al., 2014. Data mashups: potential contribution to decision support on climate change and health. Int. J. Environ. Res. Public Health 2014 (11), 1725-1746.

Foley, R., Kistemann, T., 2015. Blue space geographies: enabling health in place. Health \& Place 35, 157-165.

Fong, K.C., Hart, J.E., James, P., 2018. A review of epidemiologic studies on greenness and health: updated literature through 2017. Cur. Environ. Health Rep. 5 (1), 77-87.

Franck, U., Klimeczek, H.-J., Kindler, A., 2014. Social indicators are predictors of airborne outdoor exposures in Berlin. Ecol. Indic. 36 (2014), 582-593.

Gascon, M., Triguero-Mas, M., Martínez, D., Dadvand, P., Rojas-Rueda, D., Plasència, A. Nieuwenhuijsen, M.J., 2016. Residential green spaces and mortality: a systematic review. Environ. Int. 86, 60-67.

Gelormino, E., Melis, G., Marietta, C., Costa, G., 2015. From built environment to health inequalities: an explanatory framework based on evidence. Prev. Med. Rep. 2, 737-745.

Gibbs, E.P.J., 2014. The evolution of one health: a decade of progress and challenges for the future. Vet. Rec. 174 (4), 85-91. https://doi.org/10.1136/vr.g143.

Haaland, C., van den Bosch, C.K., 2015. Challenges and strategies for urban green-space planning in cities undergoing densification: a review. Urban For. Urban Green. 14 (4), 760-771.

Haines-Young, R., Potschin, M., 2013. Common International Classification of Ecosystem Services (CICES): Consultation on Version 4, August-December 2012 (EEA Framework Contract No EEA. Contract No EEA/IEA/09/003)

Hajat, A., Hsia, C., O'Neill, M.S., 2015. Socioeconomic disparities and air pollution exposure: a global review. Cur. Environ. Health Rep. 2, 440-450.

Hartig, T., Mitchell, R., de Vries, S., Frumkin, H., 2014. Nature and health. Annu. Rev. Public Health 35, 207-228.

Hermes, J., Van Berkel, D., Burkhard, B., Plieninger, T., Fagerholm, N., von Haaren, C. Albert, C., 2018. Assessment and valuation of recreational ecosystem services of landscapes. Ecosyst. Serv. 31 (C), 289-295.

Hidaka, B.H., 2012. Depression as a disease of modernity: explanations for increasing prevalence. J. Affect. Disord. 140 (3), 205-214.

James, P., Banay, R.F., Hart, J.E., Laden, F., 2015. A review of the health benefits of greenness. Cur. Epidemiol. Rep. 2 (2), 131-142.

Jensen, A., 2013. Controlling mobility, performing borderwork: cycle mobility in Copenhagen and the multiplication of boundaries. J. Transp. Geogr. 30, 220-226.

Jones, L., Norton, L., Austin, Z., Browne, A.L., Donovan, D., Emmett, B.A., Grabowski, Z.J. Howard, D.C., Jones, J.P.G., Kenter, J.O., Manley, W., Morris, C., Robinson, D.A., Short, C., Siriwardena, G.M., Stevens, C.J., Storkey, J., Waters, R.D., Willis, G.F., 2016. Stocks and flows of natural and human-derived capital in ecosystem services. Land Use Policy $52,151-162$.

Kabisch, N., Qureshi, S., Haase, D., 2015. Human-environment interactions in urban green spaces - a systemic review of contemporary issues and prospects for future research. Environ. Impact Assess. Rev. 50, 25-34.

Keith, A.M., Schmidt, O., McMahon, B.J., 2016. Soil stewardship as a nexus between ecosystem services and one health. Ecosyst. Serv. 17, 40-42.

Kellert, S.R., Wilson, E.O., 1993. The Biophilia Hypothesis. Island Press, Washington DC.

KPMG, 2012. Green, Healthy and Productive; The Economics of Ecosystems \& Biodiversity (TEEB NL): Green Space and Health. KPMG Advisory N.V.

Kuhlicke, C., Kabisch, S., Krellenberg, K., Steinführer, A., 2012. Urban vulnerability under conditions of global environmental change: conceptual reflections and empirical examples from growing and shrinking cities. In: Kabisch, S., Kunath, A., Schweizer-Ries, P., Steinführer, A. (Eds.), Vulnerability, Risks and Complexity: Impacts of Global Change on Human Habitats. Hogrefe (Advances in people and environment studies, 3), Göttingen, pp. 27-38.

Kuo, M., 2015. How might contact with nature promote human health? Promising mechanisms and a possible central pathway. Front. Psychol. 6.

Laatikainen, T., Tenkanen, H., Kyttä, M., Toivonen, T., 2015. Comparing conventional and PPGIS approaches in measuring equality of access to urban aquatic environments. Landsc. Urban Plan. 144, 22-33.

Laatikainen, T., Piiroinen, R., Lehtinen, E., Kyttä, M., 2017. PPGIS approach for defining multimodal travel thresholds: accessibility of popular recreation environments by the water. Appl. Geogr. 79 (1), 93-102.

Lambert, K.G., Nelson, R.J., Jovanovic, T., Cerdá, M., 2015. Brains in the city: neurobiological effects of urbanization. Neuroscience \& Biobehavioral Reviews May 1 (pii: S01497634(15)00103-7)

Lang, T., Rayner, G., 2012. Ecological public health: the 21st century's big idea? An essay by Tim Lang and Geof Rayner. BMJ 345.

Lang, D., Wiek, A., Bergmann, M., Stauffacher, Martens, P., Moll, P., et al., 2012. Transdisciplinary research in sustainability science: practice, principles, and challenges. Sustain. Sci. 7 (1), 25-43.

Markevych, I., Schoierer, J., Hartig, T., Chudnovsky, A., Hystad, P., Dzhambov, A.M., De Vries, S., Triguero-Mas, M., Brauer, M., Nieuwenhuijsen, M.J., Lupp, G., 2017. Exploring pathways linking greenspace to health: theoretical and methodological guidance. Environ. Res. 158, 301-317.

Marmot, M., Allen, J. Goldblatt, P., Boyce, T., McNeish, D., Grady, M., Geddes, I., 2010. Fair society, healthy lives. The Marmot review. Strategic Review of Health Inequalities in England Post 2010 (ISBN 978-0-9564870-0-1).

Martens, D.S., Nawrot, T.S., 2018. Ageing at the level of telomeres in association to residential landscape and air pollution at home and work: a review of the current evidence. Toxicol. Lett. https://doi.org/10.1016/j.toxlet.2018.06.1213 (in press, Available online 23 June 2018.

Milcu, A.I., Hanspach, J., Abson, D., Fischer, J., 2013. Cultural ecosystem services: a literature review and prospects for future research. Ecol. Soc. 18 (3), 44 
Mitchell, R., Popham, F., 2008. Effect of exposure to natural environment on health inequalities: an observational population study. Lancet 372 (9650), 1655-1660.

Mitchell, R.J., Richardson, E.A., Shortt, N.K., Pearce, J.R., 2015. Neighborhood environments and socioeconomic inequalities in mental well-being. Am. J. Prev. Med. 49 (1), 80-84.

OECD, 2017. Understanding the Socio-Economic Divide in Europe: Background Report. (URL). http://oe.cd/cope-divide-europe-2017.

Oosterbroek, B., de Kraker, J., Huynen, M.M.T.E., Martens, P., 2016. Assessing ecosystem impacts on health: a tool review. Ecosyst. Serv. 17, 237-254.

Paracchini, M.L., Zulian, G., Kopperoinen, L., Maes, J., Schägner, J.P., Termansen, M., et al., 2014. Mapping cultural ecosystem services: a framework to assess the potential for outdoor recreation across the EU. Ecol. Indic. 45, 371-385.

Reis, S., Morris, G., Fleming, L.E., Beck, S., Taylor, T., White, M., et al., 2013. Integrating Health \& Environmental Impact Analysis. Public Health 129 (10), 1383-1389.

Richardson, E.A., Pearce, J., Mitchell, R., Kingham, S., 2013. Role of physical activity in the relationship between urban green space and health. Public Health 127, 318-324.

Sandifer, P.A., Sutton-Grier, A.E., Ward, B.P., 2015. Exploring connections among nature biodiversity, ecosystem services, and human health and well-being: opportunities to enhance health and biodiversity conservation. Ecosyst. Serv. 12, 1-15.

Schägner, J.P., Brander, L., Paracchini, M.L., Maes, J., Gollnow, F., Bertzky, B., 2018. Spatial dimensions of recreational ecosystem service values: a review of meta-analyses and a combination of meta-analytic value-transfer and GIS. Ecosyst. Serv. 31 (C), 395-409.

Shanahan, D.F., Bush, R., Lin, B.B., Gaston, K.J., Barber, L., Dean, J., Fuller, R.A., 2015a. Towards improved public health outcomes from urban nature. Am. J. Public Health $105,470-477$

Shanahan, D.F., Fuller, R.F., Bush, R., Lin, B.B., Gaston, K.J., 2015b. The health benefits of nature: how much do we need? Bioscience 65, 476-486.

Shanahan, D.F., Bush, R., Gaston, K.J., Lin, B.B., Dean, J., Barber, E., Fuller, R.A., 2016. Health benefits from nature experiences depend on dose. Sci. Rep. 6, 28551

Sikkema, R., Koopmans, M., 2016. One Health training and research activities in Western Europe. Infect. Ecol. Epidemiol. 6, 33703.

Sze, J., London, J.K., 2008. Environmental justice at the crossroads. Sociol. Compass 2 (4), 1331-1354. https://doi.org/10.1111/j.1751-9020.2008.00131.x.

Tamosiunas, A., Grazuleviciene, R., Luksiene, D., Dedele, A., Reklaitiene, R., Baceviciene, M. et al., 2014. Accessibility and use of urban green spaces, and cardiovascular health: findings from a Kaunas cohort study. Environ. Health 13, 20.

Taylor, M.S., Wheeler, B.W., White, M.P., Economou, T., Osborne, N.J., 2015. Research note: urban street tree density and antidepressant prescription rates - a cross-sectional study in London, UK. Landsc. Urban Plan. 136, 174-179.

TEEB, 2016. The Economics of Ecosystems and Biodiversity (TEEB). (URL). http://www. teebweb.org, Accessed date: 5 December 2016.

Thompson, C.W., Aspinall, P., Montarzino, A., 2008. The childhood factor: adult visits to green places and the significance of childhood experience. Environ. Behav. 40 (1), 111-143.

Thurston, R.C., Rewak, M., Kubzansky, L.D., 2013. An anxious heart: anxiety and the onset of cardiovascular diseases. (2013). Prog. Cardiovasc. Dis. 55, 524-537.

Twohig-Bennett, C., Jones, A., 2018. The health benefits of the great outdoors: a systematic review and meta-analysis of greenspace exposure and health outcomes. Environ. Res. $166,628-637$.
Tyrväinen, L., Ojala, A., Korpela, K., Lanki, T., Tsunetsuku, Y., Kagawa, T., 2014. The influence of urban green environments on stress relief measures: a field experiment. J. Environ. Psychol. 38, 1-9.

Tzoulas, K., Korpela, K., Venn, S., Yli-Pelkonen, V., Kaźmierczak, A., Niemela, J., James, P., 2007. Promoting ecosystem and human health in urban areas using green infrastructure: a literature review. Landsc. Urban Plan. 81 (3), 167-178.

UNECE, 1998. Convention on Access to Information, Public Participation in DecisionMaking and Access to Justice in Environmental Matters. Aarhus Convention.

United Nations, 2015. Transforming Our World: The 2030 Agenda for Sustainable Development.

United Nations, Department of Economic and Social Affairs, Population Division, 2014. World Urbanization Prospects: The 2014 Revision, Highlights (ST/ESA/SER.A/352).

Van den Berg, M., Wendel-Vos, W., van Poppel, M., Kemper, H., van Mechelen, W., Maas, J., 2015. Health benefits of green spaces in the living environment: a systematic review of epidemiological studies. Urban For. Urban Green. 14 (4), 806-816.

van den Bosch, M., Sang, Å.O., 2017. Urban natural environments as nature-based solutions for improved public health-a systematic review of reviews. Environ. Res. 158, 373-384.

Wallace, R.G., Bergmann, L., Kock, R., Gilbert, M., Hogerwerf, L., Wallace, R., Holmberg, M., 2015. The dawn of Structural One Health: a new science tracking disease emergence along circuits of capital. Soc. Sci. Med. 129, 68-77.

Weinstein, N., Balmford, A. Dehaan, C.R., Gladwell, V., Bradbury, R.B., Amano, T. 2015. Seeing community for the trees: the links among contact with natural environments, community cohesion, and crime. Bioscience 65 (12), 1141-1153.

Whitmee, S., Haines, A., Beyrer, C., Boltz, F., Capon, A.G., de Souza Dias, B.F., et al., 2015. The Rockefeller Foundation-Lancet Commission on planetary health. Safeguarding human health in the Anthropocene epoch: report of The Rockefeller FoundationLancet Commission on planetary health. Lancet 386 (10007), 1973-2028 (60901-1).

WHO, 2010. Parma Declaration on Environment and Health, EUR/55934/5.1 Rev. 2. accessed on http://www.euro.who.int/_data/assets/pdf_file/0011/78608/E93618. pdf, Accessed date: 10 April 2018.

WHO, 2014. From Amsterdam to Paris and Beyond: The Transport, Health and Environment Pan-European Programme (THE PEP) 2009-2020. WHO Regional Office for Europe, Copenhagen, Denmark.

WHO, 2015. Factsheet no 369. (URL). http://www.who.int/mediacentre/factsheets/fs369/ en/, Accessed date: 30 November 2015.

WHO, 2018. European Environment and Health Process (EHP). Accessed. http://www. euro.who.int/en/health-topics/environment-and-health/pages/european-environment-and-health-process-ehp, Accessed date: 10 April 2018.

Wilcox, B.A., Aguirre, A.A., Daszak, P., Horwitz, P., Martens, P., Parkes, et al., 2004. EcoHealth: a transdisciplinary imperative for a sustainable future. EcoHealth 1 (1), 3-5. https://doi.org/10.1007/s10393-004-0014-9.

World Resources Institute, 2014. http://www.griequity.com/resources/Environment/ Global\%20Environmental\%20Trends.htm, Accessed date: 17 September 2014. 